\title{
Stock depletion of yellowfin tuna Thunnus albacares (Bonnaterre 1788) in the Northeastern Indian Ocean
}

\author{
Bram Setyadji ${ }^{1, *}$, Hety Hartaty $^{1}$, Arief Wujdi ${ }^{1}$, and Ririk K. Sulistyaningsih ${ }^{1}$ \\ ${ }^{1}$ Research Institute for Tuna Fisheries, Denpasar, Bali, Indonesia - 80224
}

\begin{abstract}
The stock of yellowfin tuna (Thunnus albacares) has been in a declining trend in the last five years. Although the noticeable decline mainly occurred in the western part of the Indian Ocean, uncertainty lingers on how this phenomenon will affect the opposite leg. The study aimed to investigate the dynamics of stock through monitoring several indicators by utilizing logbooks, scientific port sampling, and observer data available. The result showed that both relative abundance and estimated catch trend are declining in recent years, a sign that the negative global inclination also influences Indonesian tuna longline fisheries. Further studies are needed to understand whether this phenomenon also impacts other gears. Hence, mitigation on conserving the resource by reducing the catch and strengthening the data collection should be the priority to maintain the livelihood and welfare of many coastal communities.
\end{abstract}

\section{Introduction}

Yellowfin tuna (Thunnus albacares) is probably considered one of the most exploited fish in the world [1-3]. They are an integral part of coastal and industrial fisheries in the Pacific, Atlantic, and Indian Ocean [4]. The juveniles primarily interact with the surface gears $[5,6]$, whereas the adult mainly becomes a target for longline fleets [7]. The recent catch from the Indian Ocean estimated around 427,239 tons and ranked second among three RFMOs (Regional Fisheries Management Organization) [8-10]. Iran, Maldives, European Union (Spain and France), Seychelles, and Sri Lanka are the leading fishing nations, comprising more than $60 \%$ of the total catch. In contrast, Indonesia only contributed around $6 \%(\sim 20,000$ tons) [8], despite reported close to 40,000 MT in recent years [11]. The discrepancies occurred due to the re-estimation process conducted by the IOTC (Indian Ocean Tuna Commission) secretariat after finding inconsistencies in the data submitted [12].

The current yellowfin tuna stock in the Indian Ocean is assessed in overfished and has become a subject of overfishing [8] for the last five years. Even though the cause is not well understood due to various uncertainties, but the increasing catch from drifting fish aggregating device (DFAD), purse seine, and gillnet fleets since the 1980s has kept the

* Corresponding author: bramsetyadji@kkp.go.id 
yellowfin catch at a high level, surpassed the longline catch [8]. Intensive fishing pressure remained, despite the brief absence (2007-2011) when piracy activities off Somalia's coast intensified [13]. Hence, the increase in catches in recent years has substantially increased the pressure on the stock, thus exceeding the maximum sustainable yield (MSY) level [8]. Historically, the high fishing areas occurred within the western Indian Ocean, e.g., around Seychelles, waters off Somalia, and the Mozambique Channel, and it's still unclear whether the depleting stock also affects the "less intense zone," i.e., eastern Indian Ocean.

Our analytical objective was to give some evidence amid stock changes of yellowfin tuna from the Indonesian tuna longline perspective to represent the condition in the eastern Indian Ocean by utilizing fisheries independent data (scientific port sampling and observer program). We believe the results are valuable as auxiliary information to assess the status of yellowfin as a whole unit of stock.

\section{Materials and methods}

\subsection{Data Collection}

There are two primary data sources used for this study. The first is the scientific observers' program (2006-2020), and the latter is a port sampling program (2012-2020), all the data obtained with permission from the Research Institute for Tuna Fisheries (RITF), Bali. The catch (number of individual fish) and effort (number of hooks per set) are needed to model the relative abundance of yellowfin over time. The data then overlayed with catch estimation from the Benoa fishing port. Additional information such as spatial distribution and abundance from the previous study [14] was also added.

\subsection{Data filtering}

The primary issue for calculating the abundance from Indonesian tuna longline fishery was the high proportion of zero-catch-per-set [15]. The mean annual proportion of zero catches from the data was relatively high $(\sim 60 \%)$ and likely overdispersed. In an attempt to reduce it, several ways were conducted as follows:

1. Data from 2005 were excluded from analysis since it was the beginning of the scientific observer program since it was undertaken only for seven months and high likely contained species misidentification;

2. Data used for analysis limited only from $5 \mathrm{~N}$ to $17.5 \mathrm{~S}$ (northeastern Indian Ocean) due to low spatial coverage outside the "core area";

3. Excluding a trip that doesn't contain yellowfin catch.

\subsection{Data analysis}

The catch-per-unit-of-effort (CPUE) was calculated as the number of yellowfin caught per 100 hooks, and the zero-catch-per-set was included when calculating the mean. The series combined with older references from commercial logbook data around 1979-1995 [16]. Over time, patterns in relative abundance were visualized by fitting the data with a non-parametric approach (locally weighted scatterplot smoothing) as implemented in R's ggplot2 Generalized Additive Model (GAM) method. Local fitting uses the distance of data in the neighborhood of each dependent variable (Year) to weigh the least-squares of the independent variable (relative abundance of yellowfin). Its size is controlled by the ggplot's 
span parameter in geom_smooth or stat_smooth function. A retrospective analysis was conducted [17] to analyze the base case (1978-2019) by sequentially removing the most recent year (retrospective "peel") and refitting the model over five years (i.e., 2019 back to 2015).

On the other hand, the catch estimation from Benoa fishing port was counted using a proposed formula from IOTC [18], intended explicitly for longline, as follows:

$$
C M=L M * A V M
$$

Where:

$C M$ : Estimated catch $(\mathrm{kg})$

$L M$ : Total number of landings (unit)

$A V M$ : Total yellowfin sampled (kg)/total number of vessels sampled (unit)

Before estimation, the individual processed weight was converted to whole weight using raising factor developed by FAO [19], which is 1.1 for yellowfin. The annual mean length was also investigated with the local polynomial regression fitting (LOESS) method [20] to see any changes in its size distribution over time. Maps were produced using QGIS version 3.18 [21], and the statistical analyses were carried out using R software version 3.4.0 [22], particularly the ggplot2 package [23].

\section{Results}

\subsection{Relative abundance}

The catch and effort data of Indonesian tuna longline fleets are distributed mainly in the northeastern Indian Ocean. Most of the previously recorded data and observations were conducted in the western and southern part of Indonesian waters, between $0^{\circ}-35^{\circ} \mathrm{S}$ and $75^{\circ}$ $125^{\circ} \mathrm{E}$ (Fig. 1.). Indonesian tuna longline fleets had targeted yellowfin tuna since the late 1970s when the commercial fisheries and early data collection took place. At the beginning of the series, the catch rate was high, around 0.75 fish/100 hooks. After reaching its peak in 1982 ( 1.00 fish/100 hooks), the catch rate declined substantially until the 2000s, before the series recovered slightly for the next decade. Due to the high catch in 2019 , the trend after 2010 was driven in a positive direction. However, the retrospective analysis showed that it was going on the opposite side (Fig. 2.). A high degree of uncertainty between 1996-2005 occurred when the data was absent. Nevertheless, the GAM-fitted trend was able to capture and predict the missing values.

\subsection{Catch trends}

The total estimated catch from Indonesian tuna longline fleets based in Benoa Port was varied over the years. After a positive trend for three consecutive years and reached its peak with approximately 3,000 MT, the catch started to decline sharply to only less than half of the catch in 2014, around 1,000-1500 MT, with exclusion from 2016 where the catch was substantially high around 2,500 MT (Fig. 3.). 


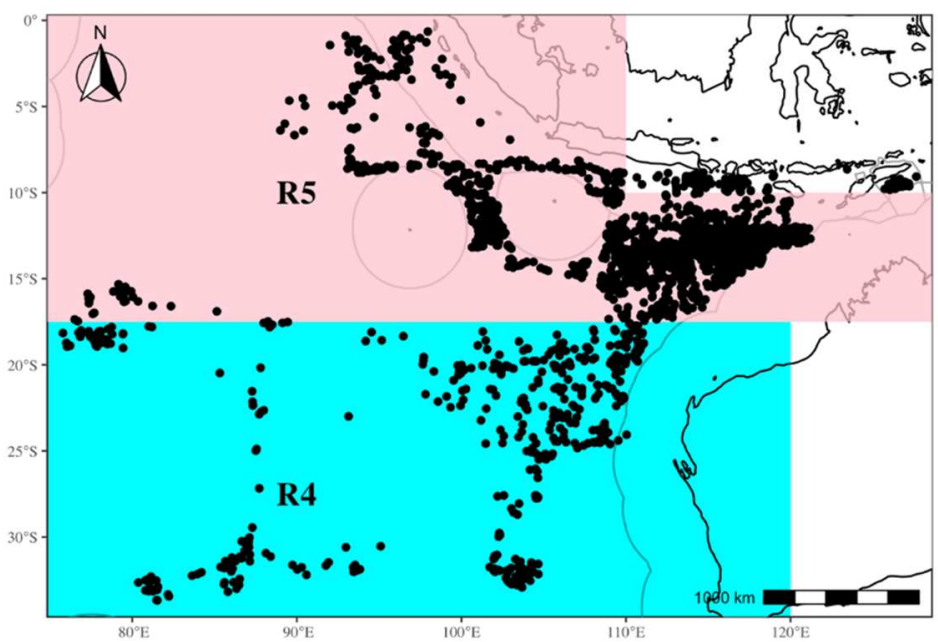

Fig. 1. The distribution of the Indonesian tuna longline efforts extracted from scientific observer data from 2006-2019. The shaded areas represent regional structures used to estimate yellowfin CPUE indices (See Hoyle [24]).

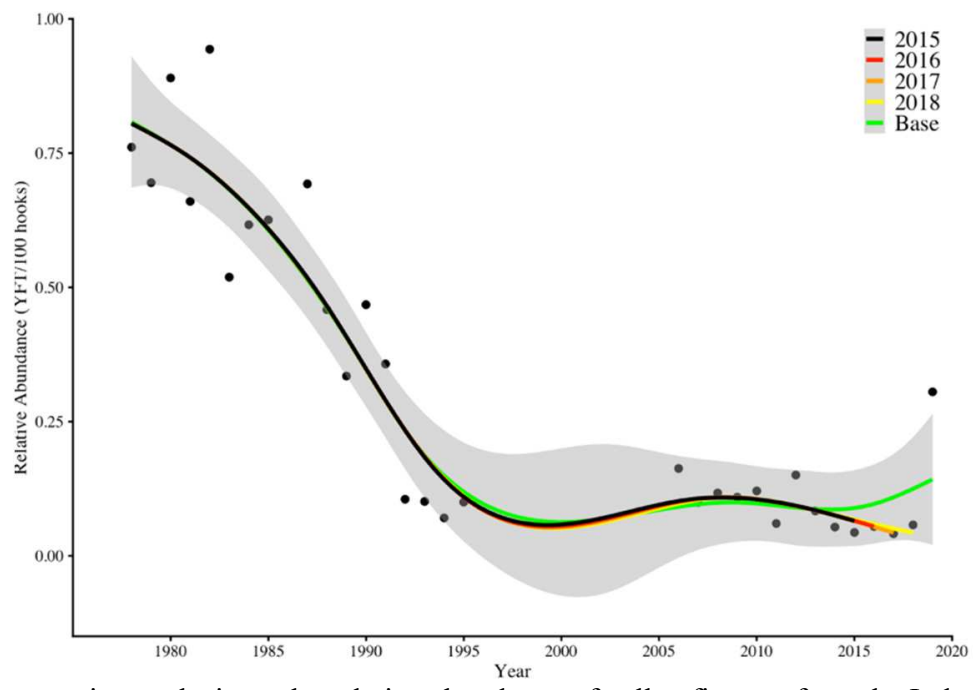

Fig. 2. Retrospective analysis on the relative abundance of yellowfin tuna from the Indonesian tuna longline fleets. The early data (1978-1995) was reproduced from Sadiyah, Dowling, and Prisantoso [25], whereas the latter (2006-2019) was generated from scientific observer data. The grey areas represent the range of $95 \%$ confidence intervals. 


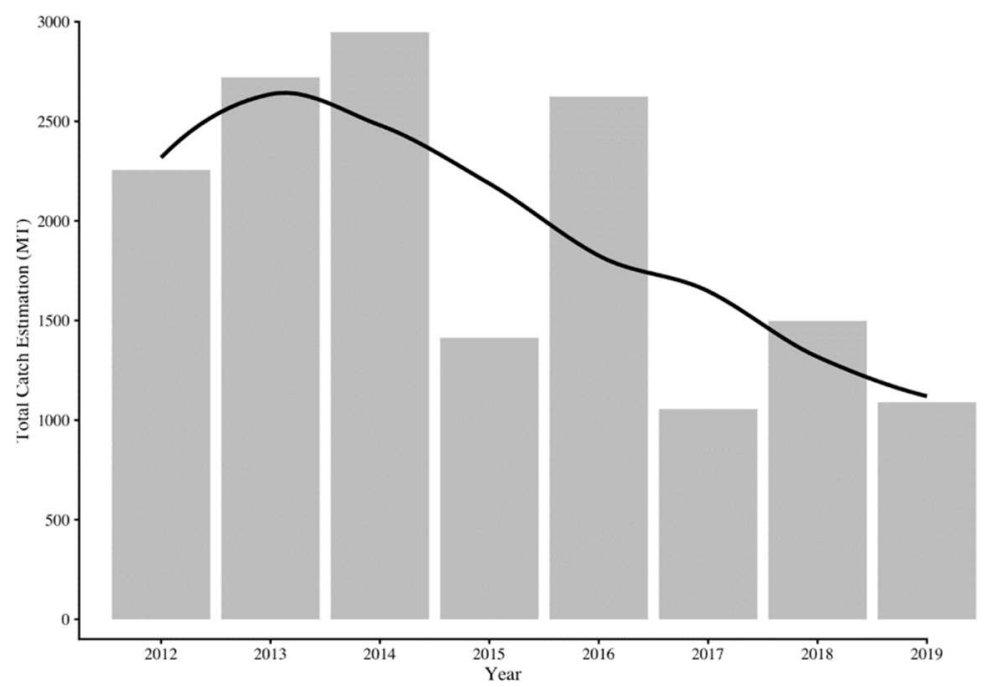

Fig. 3. Estimated catch (in metric tons) of yellowfin tuna landed in Benoa Port from 2012-2020.

Remarks: The processed weight (gilled and gutted) has been converted to whole weight. The line represents the LOESS smoothing method.

\subsection{Size distribution trends}

A total of 45,626 morphometric measurement data was collected, with an average of $5069.5+2025.9$ per year. In general, the mean length of yellowfin tuna showed a slight rise between 2012-2016, ranged $121.1 \pm 0.3$ to $139.1 \pm 0.2 \mathrm{cmFL}$. The lowest mean remarks the occurrence of many small fishes at the start of the series. Afterward, the series faced a dip for three consecutive years (133.9 $\pm 0.3-128.4 \pm 0.2 \mathrm{cmFL})$. Although there was a bouncing point in 2019, the trend remained in a negative state. Nevertheless, the series generally falls above its length at $50 \%$ mature, about 102-113 cmFL [26, 27] (Fig. 4.).

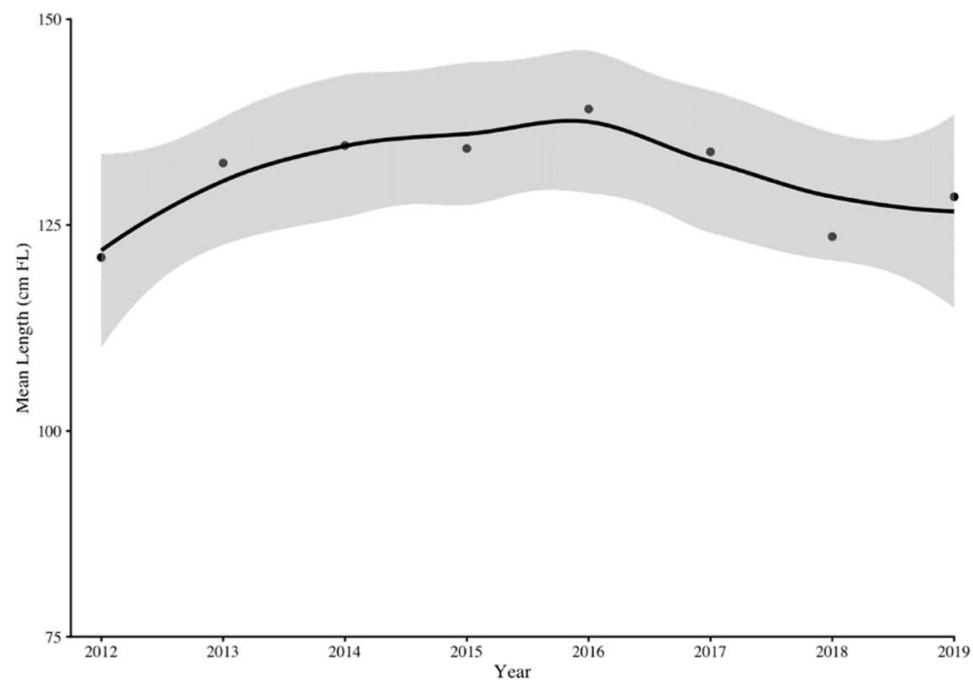

Fig. 4. The median length trend of yellowfin tuna landed in Benoa Port from 2012-2019. The gray areas represent the range of $95 \%$ confidence intervals. 


\section{Discussion}

The signs of a declining abundance of yellowfin tuna in the Indian Ocean are confirmed by indices from longline fleets and other gears, especially in the tropical areas close to the equator [24], which are associated with more significant depletion areas of purse seine fishing [28]. However, uncertainties occurred when dealing with gillnet and miscellaneous gears because these were poorly estimated [29]. In the northeastern area, especially in the earlier series, the downfall was likely driven by the shifting from surface to the deep longline technique, targeting bigeye instead of yellowfin tuna in the early 1980s [14]. However, the transition only occurred in 1992, where the catch rate of bigeye tuna surged, and yellowfin started to stabilize [25]. Japanese and Taiwanese longline fleets [30, 31], specifically in the last two decades. A worrying alert to the abundance of yellowfin tuna stock in this area. A remark on the high spike in 2019 was allegedly an anomaly, where a few sets resulted in an increased number of fishes. The retrospective analysis verified that, when the simulation took one year, the series showed a negative trend until the last five years.

Benoa port is considered an integral part of tuna production in Indonesia, contributing at least $15 \%$ of the yellowfin tuna from all longline fleets in the last five years [11]. The estimated catch trend was varied over the years. However, the tendency led to a weakening state after 2014 despite the spike in 2016. A strict ban on ex-foreign vessel permits in 2014 due to the Ministry of Marine Affairs Regulation No. 56 in 2014 had caused a severe reduction of the number of boats [32] and landing frequency [11]. In addition, Rochman, Setyadji, and Jatmiko [33] investigation found no significant difference in total catch estimation before and after the policy. Instead, it implicates the decline of the fresh tuna export instead by $-13 \%$ [32]. So, lower fishing effort (unit/frequency) is not directly affecting the cutback on yellowfin tuna catch after 2014. By contrast, the declining abundance is likely the driving force.

In recent years, the annual mean length obtained from the port sampling program also confirmed the possible stock depletion by reduced average yearly length values. Japanese longline fleets also reported the same issue since the mid-1990s, where the mean size was shrunk $15 \%$ from the beginning of the series [34]. Life-history traits are vulnerable to environmental stress and fishing pressure [35], resulting in smaller mature fishes as a response for survival. However, since longline gear characteristically captures more giant tunas [36], thus generated higher selectivity for many target species [37, 38] than other gears, e.g., purse seine. However, although the overall trend remains above the minimum threshold of its maturity level, the minor occurrence of yellowfin tuna in recent years shouldn't be ignored.

In the bigger picture, longline catches are not solely responsible for the rapid depletion of main tuna species, especially yellowfin tuna [39]. Instead, the significant increases in catches in recent years are likely to be the driving force. Half of it is from net-constructed gears [8], exceptionally by European Union high seas purse seiners. The intensive fishing in the western part of the Indian Ocean had brought a domino effect to the eastern counterpart in the last few decades, resulting in lower abundance, catch, and smaller fish. Responding to this issue, coastal and distant fishing nations agreed on the interim plan to rebuild yellowfin stock through IOTC Resolution 19/01. The agreement regulated reducing the catch of yellowfin tuna by $15 \%$ for purse seine, $10 \%$ for longline and gillnet, and $5 \%$ for miscellaneous gears based on the 2014 catch. In addition, reducing the carrier vessels and a strong recommendation for converting gillnet to other fishing gear were also formulated. Unfortunately, the detailed action plan failed to materialize by the members, allowing more time for overfishing. Many experts believe that 2021 will be the last chance for saving the stock, whereas, based on the 2017 catch, a $25 \%$ reduction of the annual total catch is needed 
to achieve at least a $50 \%$ probability of recovering in 2027 [40, 41].

\section{Acknowledgements}

The authors wish to thank the scientific observers and enumerators who performed invaluable roles in fisheries data collection as part of the Australian Centre for International Agricultural Research Project (ACIAR) FIS/2002/074, and subsequently for Research Institute for Tuna Fisheries (2011 and onwards).

\section{References}

1. Y. Zhang, Y. Chen, J. Zhu, S. Tian, X. Chen, Aqua. Fish. 2, 84 (2017)

2. K. Nimit, N.K. Masuluri, A.M. Berger, R.P. Bright, S. Prakash, U. TVS, S.K.T, P. Rohit, T.A, S. Ghosh, S.P. Varghese, Int. J. Remote Sens. 41, 5785 (2020)

3. E. Dortel, F. Sardenne, N. Bousquet, E. Rivot, J. Million, G. Le Croizier, E. Chassot, Fish. Res. 163, 69 (2015)

4. K.-W. Yen, H.-J. Lu, Y. Chang, M.-A. Lee, Int. J. Remote Sens. 33, 7507 (2012)

5. A. Fonteneau, E. Chassot, N. Bodin, Aquat. Living Resour. 26, 37 (2013)

6. E.V. Romanov, Fishery Bulletin 100, 90 (2002)

7. H.-W. Huang, K.-M. Liu, Fish. Res. 106, 261 (2010)

8. IOTC-WPTT22, Report of the 22nd Session of the IOTC working party on tropical tunas, stock assessment meeting (Indian Ocean Tuna Commission, Online, 2020)

9. WCPFC Secretariat and Oceanic Fisheries Programme (OFP) Pacific community (SPC), Catch and effort tables on tropical tuna CMMS (Western and Central Pacific Fisheries Commission (WCPFC), Online, 2020)

10. ICCAT, Statistical Bulletin, 46 (2020)

11. Z. Fahmi, Y. Hikmayani, T. Yunanda, P. Yudiarso, W. Wudianto, B. Setyadji, Indonesia national report to the scientific committee of the Indian Ocean Tuna Commission 2020 (Indian Ocean tuna Commission, Online, 2020)

12. IOTC-WPDCS14, Report of the 14th session of the IOTC working party on data collection and statistics (Indian Ocean tuna Commission (IOTC), Victoria, 2018)

13. IOTC, Non-Goverment organization statement at 25th session of the Indian Ocean Tuna Commission (IOTC, Online, 2021)

14. L. Sadiyah, B.I. Prisantoso, Ind. Fish. Res. J. 17, 29 (2011)

15. L. Sadiyah, N. Dowling, B. I. Prisantoso, Ind. Fish. Res. J. 18, 19 (2012)

16. B. Gafa, S. Bahar, A.A. Widodo, B.I. Prisantoso, M. Mahiswara, E. Rachmat, K. Susanto, J. Uktolseja, K. Wagiyo, I. N. Radiarta, T. Nishida, 2nd Session of the Working Party on Tropical Tunas, (2000)

17. R. Mohn, ICES Journal of Marine Science 56, 473 (1999)

18. IOTC, Field manual for data collection on tuna landings from longliners (Indian Ocean tuna Commission, Secychelles, 2002)

19. FAO, Conversion factors - landed weight to live weight, Rev. 1 (FAO, Rome, 2000)

20. W. S. Cleveland, E. Grosse, W. M. Shyu, in Chapter 8 in statistical models, edited by J. M. Chambers, T. J. Hastie (Wadsworth \& Brooks/Cole, Pacific Grove, CA, 1992) 
21. Q.D. Team, QGIS geographic information system (Open Source Geospatial Foundation Project, 2020)

22. R Core Team, R: a language and environment for statistical computing (R Foundation for Statistical Computing, Vienna, 2020)

23. H. Wickham, Ggplot2: elegant graphics for data analysis (Springer-Verlag, New York, 2016)

24. S.D. Hoyle, E. Chassot, D. Fu, D.N. Kim, S.I. Lee, T. Matsumoto, K. Satoh, S.-P. Wang, Y.-M. Yeh, T. Kitakado, 9th Working Party on Methods IOTC, (2018)

25. L. Sadiyah, N. Dowling, B.I. Prisantoso, Indones. Fish. Res. J. 17, 87 (2011)

26. I. Zudaire, H. Murua, M. Grande, N. Bodin, Fish. Bull. 111, 252 (2013)

27. G. Zhu, L. Xu, Y. Zhou, L. Song, J. Ocean Univ. China 7, 327 (2008)

28. J. Santiago, J. Uranga, I. Quincoces, B. Orue, M. Grande, H. Murua, G. Merino, A. Urtizberea, P. Pascual, G. Boyra, 21st Working Party on Tropical Tuna, (2019)

29. ISSF, Status of the world fisheries for tuna: March 2021 (International Seafood Sustainability Foundation (ISSF), Washington, 2021)

30. T. Matsumoto, S.D. Hoyle, 21st Working Party on Tropical Tuna, (2019)

31. Y.-M. Yeh, W.-P. Tsai, S.-T. Chang, S.D. Hoyle, 21st Working Party on Tropical Tuna, (2019)

32. S. Saptanto, R. Yusuf, T. Apriliani, F.Y. Arthatiani, J. Kebijakan Sosek KP. 5, 137 (2015)

33. F. Rochman, B. Setyadji, I. Jatmiko, J. Lit. Perikan. Ind. 22, 181 (2016)

34. M. Basson, N. Dowling, 6th Session of the Working Party on Tropical Tunas (2004)

35. J. Goldstein, S. Heppell, A. Cooper, S. Brault, M. Lutcavage, Mar. Biol. 151, 2063 (2007)

36. V. E. Brock, Pac. Sci. 16, 3 (1962)

37. J.W. Watson, D.W. Kerstetter, Mar. Technol. Soc. J. 40, 6 (2006)

38. S. Løkkeborg, Å. Bjordal, Fish. Res. 13, 311 (1992)

39. T. Polacheck, Mar. Policy 30, 470 (2006)

40. IOTC-SC022, Report of the 22nd session of the IOTC scientific committee (Indian Ocean Tuna Commission, Karachi2019)

41. J. Rattle, Blue marine foundation - a case study for the management of yellowfin tuna by the IOTC (Blue Marine Foundation, Hyderabad, 2019) 